\title{
A NEW METHOD FOR THE DETERMINATION OF TOXIC DYE USING FTIR SPECTROSCOPY
}

\author{
Mohamed E. S. Mirghani ${ }^{1}{ }^{*}$, NASSEREldeen A. KABbashi ${ }^{1}$, ISAM Y. QUdSIEH ${ }^{1}$ \\ AND FAIZ A. ELFAKI ${ }^{2}$ \\ ${ }^{1}$ Bioenvironmental Engineering Research Unit (BERU), Department of Biotechnology \\ Engineering, ${ }^{2}$ Department of Science in Engineering, Kulliyyah of Engineering, International \\ Islamic University Malaysia (IIUM), P. O. Box 10, 50728 Kuala Lumpur, Malaysia \\ *E-mail:elwathig@iiu.edu.my
}

\begin{abstract}
A new method was developed to determine toxic dyes content in textile and other products using Fourier Transform Infrared (FTIR) spectroscopy with Attenuated Total Reflectance (ATR) element and $\mathrm{KBr}$ transmission cell. The wavelengths used were selected using pure dyes and dye mixtures. Transmittance values from the wavelengths regions $3500-2650$ and $1675-1500 \mathrm{~cm}^{-1}$ and partial least square (PLS) regression method were used to derive FTIR spectroscopic calibration model for dyes containing $-\mathrm{N}=\mathrm{N}-$ in their structure. The coefficient of determinations $\left(\mathrm{R}^{2}\right)$ for the models were computed by comparing the results obtained from FTIR spectroscopy against the actual values of the dyes concentrations. $\mathrm{R}^{2}$ were 0.9321 and 0.9819 for two samples of toxic dyes respectively. The standard errors (SE) of calibrations were 1.84 and 1.36 respectively. The calibration model was cross validated within the same set of samples and the standard deviation (SD) of the difference for repeatability and accuracy of the FTIR method were determined. With its speed and ease of data manipulation, FTIR spectroscopy is a useful alternative method to wet chemical methods for rapid and routine detection of azo dyes as toxic dyes in such products for quality control.
\end{abstract}

KEYWORDS: FTIR spectroscopy, PLS, Toxic dye.

\section{INTRODUCTION}

Dyeing is an ancient art which predates written records. It was practiced during the Bronze Age in Europe [1]. Primitive dyeing techniques include sticking plants to fabric or rubbing crushed pigments into cloth. Nowadays, most of the colors used commercially for dyeing are synthetic, which mostly derived from non-renewable coal tar and petroleum. They are synthesized by various means, from by-products of fossil fuels, e.g., aniline and other aromatic derivatives [2]. Because clothing comes into prolonged contact with skin, toxic chemicals are absorbed through the skin, especially when human body is warm and skin pores have opened to permit perspiration. Once absorbed by humans, heavy metals tend to accumulate in the liver, kidney, bones, heart and brain. The effects on health can be significant when high levels of accumulation are reached. The effect is particularly serious in children because toxic dye and/or heavy metals accumulation may negatively affect their growth and may be their life as well. 
It is often the dye fixative which is used to bond the dye color to the fabric that causes the most problems. Unfortunately, heavy metals have often been used in dye fixatives and also in dyes. Toxic chemicals sometimes found in the dyeing process include:

- Dioxin - a carcinogen and possible hormone disrupter.

- Toxic heavy metals such as chrome, copper, and zinc - known carcinogens.

- Formaldehyde - a suspected carcinogen.

- Azo dyes group - which give off carcinogenic amines.

In general, azo dyes can occur in two tautomeric forms; azo $(-\mathrm{N}=\mathrm{N}-)$ or hydrazone $(=\mathrm{N}-\mathrm{NH}-)$. The latter is said to be more prone to the oxidative fading, which is the most common photodegradation mechanism in the presence of light, moisture, and oxygen. In oxidation of an azo dye, singlet oxygen attacks on the hydrazone tautomer to form unstable peroxide, which then undergoes decomposition. Under anaerobic conditions, azo dye can be reduced to its corresponding amines by abstracting a hydrogen atom from a hydrogen donor [3].

Amendments and regulations in some countries stated that azo-dyestuffs, which can release carcinogenic amines, should no longer be used in dyeing consumer goods. ${ }^{13} \mathrm{C}$ and ${ }^{15} \mathrm{~N}-\mathrm{NMR}$ studies of the azo-hydrazone tautomerism of some azo dyes were carried out by Antonin and Valdimir [4]. Many acid and direct dyes which liberate harmful amines such as benzidine, $o$-tolidine and $o$-dianisidine after reduction are, however, still used [5]. Toxic chemicals from dyes also create widespread environmental havoc. Large amounts of water are used to flush conventional synthetic dyes from garments and then this waste water must be treated to remove the heavy metals and other toxic chemicals before it can be returned to water systems, sewers and rivers.

Most garments are produced in developing countries where pollution controls are often lax or nonexistent. Discharges from huge numbers of the textile producers go straight into rivers where the river water might be bright green one day and yellow the next. Developing countries are also lacking in standards and enforcement concerning the use of toxic chemicals in dyes and garment finishes. Figures 1 and 2 showed the chemical structure of some of the first commercial cellulosic fiber-reaction dyes used in fabric industries that make use of the mono-chlorotriazinyl group. Figure 3 shows an orange dye that is covalently bonded with the cotton fiber.

Low-impact, fiber-reactive dyes have become the dye of choice for many organic clothing manufacturers who want a diverse palette of vibrant colors. Depending upon the nature and degree of their chemical sensitivities, people with mild chemical sensitivities can often wear organic clothing with fiber-reactive dyes. Un-dyed, natural color or colorgrown fabrics are the best choice for people who react to fiber-reactive dyes or who want only pure fabrics on their skin.

As the awareness of the need to preserve our natural resources and environmental factors increases, interest is growing in finding renewable resources, which can be used as alternatives. Natural dyes are seen as more eco-friendly as, unlike their synthetic 
counterparts, they are all derived from nature. Production of natural indigo from plant material (Polygonum tinctorium Ait) applying low-technology methods was done successfully by Bechtold et al. [6]. A better quality indigo dyestuff was extracted from the indigo plant (Indigofera tinctoria L.) [7].

Earlier all colors were derived from natural sources, including plants. Looking for better quality colors for industry, researcher went to the synthesis of dyes from byproducts of the petrochemical. Recent research is looking for the possibility to use plants as commercially viable source of dyes [8]. This means that in order to satisfy the demand for high quality and choice, the plants in question must be studied more closely to allow breeding of useful lines and improved economic returns.

In this study, an FTIR spectroscopy was used to develop qualitative and quantitative analytical environmentally friendly technique for different types of dyestuffs or dyed substrates.<smiles>NS(=O)(=O)c1cc(Nc2ccc(Nc3nc(Cl)nc(Cl)n3)cc2)c2c(c1)C(=O)c1c(Br)ccc(Br)c1C2=O</smiles>

Fig. 1: Anthroquinonoid reactive dye (Procion Blue).<smiles>O=[N+]([O-])c1cc2cc(S(=O)(=O)O)cc(Nc3nc(Cl)nc(Nc4ccccc4)n3)c2c(O)c1N=Nc1ccccc1S(=O)(=O)O</smiles>

Fig. 2: Procion Brilliant Red. 


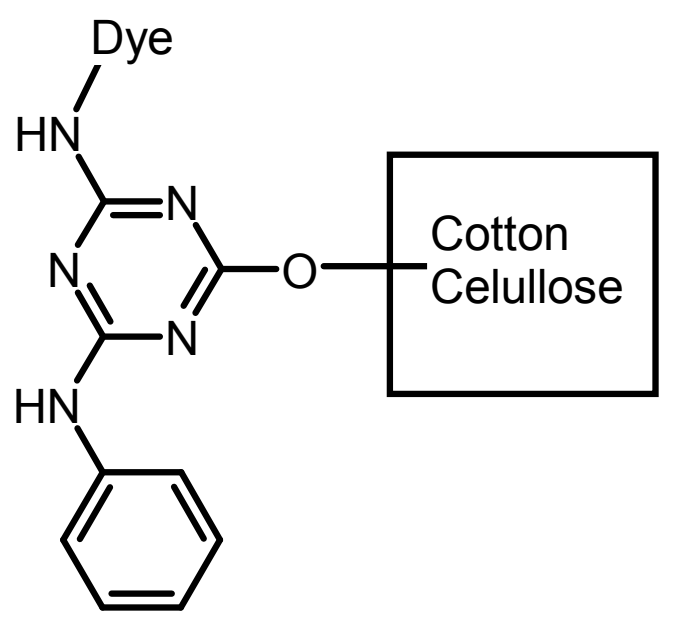

Fig. 3: Reactive orange dye covalently bonded with the cotton fiber.

\section{MATERIALS AND METHODS}

\subsection{Samples and Chemicals}

All chemicals were of analytical grade. Different types of dyes samples were purchased from local market. Fabric and hair dyes samples were used in this study. Solid samples were used to make stock solution followed by preparing dilutions of known concentrations ranged from 0 to $80 \mathrm{mg} / \mathrm{mL}(\mathrm{w} / \mathrm{v})$ to be used as standard solutions. The samples were tightly covered and shaken vigorously to homogeneity on an Autovortex SA1 mixer (Stuart Scientific, Redhill, UK).

\subsection{Chemical Analysis}

Hair dyes and some fabric dye samples were determined by photometry using alkaline solutions of $\mathrm{Fe}$ (II) triethanolamine as reducing agent following the methods suggested and used by Bechtold et al. [9] and Merritt et al. [10] respectively, after some modifications on handling samples.

\subsection{Instrumental Analysis}

The infrared spectra were recorded at room temperature with a Perkin-Elmer Fourier Transform Infrared Spectrometer, Model spectra 100 series (Perkin-Elmer Corporation, Norwalk, CT, USA), equipped with a deuterated triglycine sulfate (DTGS) detector and controlled by a Perkin-Elmer PC. The software used for the FTIR data collection was the Infrared Data Management (IRDM) system. The instruments were maintained in constant humidity to minimize water vapor interference.

Drops from each standard were placed on ATR element and scanned. After each scan, the ATR diamond were rinsed three times with acetone and dried with soft tissue before adding the next sample. Calibration spectra were obtained from 64 scans at a resolution of 
$2 \mathrm{~cm}^{-1}$ with strong apodization through $4000-400 \mathrm{~cm}^{-1}$ frequency region. The spectra were ratioed against the background air spectrum. All the scans were done in triplicate with the spectra recorded as absorbance and stored on a disk for subsequent chemometric analysis.

\subsection{Statistical Analysis}

All the experiments and measurements were done in triplicate. The relationships between each of the FTIR spectrum parameter and the original data from the standard solutions were determined using the software Nicolet Turbo Quant IR-Calibration and Prediction Package, Version 1.1 (Nicolet Instrument Co., Madison, WI, USA).

PLS regression was used to derive the dye contents in the standard solutions. The actual and spectral data were correlated and the correlation coefficients (r) taken as estimates of the factor scores, which were then used as regressors to model both the spectral and actual data. Selected factors were used in a multiple linear regression (MLR) to predict the spectral values. The optimum number of factors employed in the calibrated models was indicated by the predicted residual error sum of squares (PRESS) values. An example of the PRESS plot is shown in Fig. 11, which also shows the $F$-test significance result for the method $(<0.05)$ and number of factors included in the calibration at the lowest value. The $F$ statistic for each PRESS value was calculated with all the factors prior to the number with the smallest PRESS value. The optimum number of factors was empirically chosen as that which gave the smallest PRESS value such that the $F$ ratio probability drops below 1.0 or below 0.75 .

Microsoft Excel spreadsheet software was used to organize the correlation of the FTIR predicted and actual or chemical data. The good correlation obtained for the 30 calibration samples indicated the adequacy of the FTIR calibration. Accuracy was assessed based on the smallest standard error (SE) and the highest coefficient of determination $\left(\mathrm{R}^{2}\right)$ [11].

\subsection{Validation}

The 'leave-one-out' cross-validation technique was used to verify the calibration model. The PRESS was computed from the error in prediction from the standards and plotted as a function of the number of factors employed in the calibration. The accuracy was assessed by the standard error of cross validation (SECV) and $\mathrm{R}^{2}$. Further verification was by the mean difference (MD) and standard deviation of difference (SDD) for repeatability and closeness of fit (accuracy) between the chemical data and FTIR predicted values.

\section{RESULTS AND DISCUSSION}

\subsection{Chemical and FTIR Predicted Results}

Table 1 shows the FTIR predicted values by the PLS statistical method as means and standard deviations (SD) of the actual manually prepared data (Standard solutions) for dye contents in the samples. The means and SDs for fabric dye were 46.53, 4.05 and 44.17, 
$3.75 \mathrm{mg} / \mathrm{kg}$ for calibration and cross-validation, respectively. For hair dye, they were $45.20,3.69$ and $45.82,3.85 \mathrm{mg} / \mathrm{kg}$, respectively.

Table 1: Calibration and cross-validation for dye content in fabric and hair dye samples by FTIR methods in comparison with actual values of dye concentration. ${ }^{\text {a }}$

\begin{tabular}{lccccc}
\hline & \multicolumn{2}{c}{ Fabric dye } & & \multicolumn{2}{c}{ Hair dye } \\
\cline { 2 - 3 } \cline { 5 - 6 } Data Set & Mean & SD & & Mean & SD \\
\hline Calibration & 46.53 & 4.05 & & 45.20 & 3.69 \\
Validation & 44.17 & 3.75 & & 45.82 & 3.85 \\
\hline
\end{tabular}

${ }^{a}$ FTIR, Fourier transform infrared spectroscopy; SD, standard deviation; All dataset obtained from three replications.

Figures 4, 5 and 6 illustrate the spectra for dying stuff samples of hair dye, green dye, and henna, respectively. The spectra are in the frequency range $4000-400 \mathrm{~cm}^{-1}$. Each spectrum showed the characteristic absorption bands of dyeing stuff according to its chemical structure $[12,13]$. Figure 4 shows bands at 2020, 1480 and $1419 \mathrm{~cm}^{-1}$ which indicates the presence of alkyl groups. The band at $1510 \mathrm{~cm}^{-1}$ could be assigned for the aromatic compound possibly nitrile type compound alkyne ( $\equiv \mathrm{C}-\mathrm{C},-\mathrm{C} \equiv \mathrm{N}$, and $-\mathrm{N}=\mathrm{N}-$ ) or isocyanate $(-\mathrm{N}=\mathrm{C}=\mathrm{O})$. The band at $1033 \mathrm{~cm}^{-1}$ could be assigned for carboxylic acid ester ( $\mathrm{R}-\mathrm{CO}-\mathrm{O}-\mathrm{C}-)$ or $(\mathrm{R}-\mathrm{CO}-\mathrm{N}-)$. The bands at 856 and $691 \mathrm{~cm}^{-1}$ could be assigned for aromatic ring and $-\mathrm{C}=\mathrm{S}=\mathrm{C}-$, respectively. The spectrum of green dye (Fig. 5) shows bands at $3308 \mathrm{~cm}^{-1}$ and $2970 \mathrm{~cm}^{-1}$ which could be assigned for overlaps of the $\mathrm{C}-\mathrm{H}$ stretching region and methyl $\mathrm{C}-\mathrm{H}$ asymmetric stretch, respectively. The band at $1738 \mathrm{~cm}^{-1}$ indicated the presence of carbonyl group $(-\mathrm{C}=\mathrm{O}), 1635 \mathrm{~cm}^{-1}$ may be assigned for quinine or conjugated ketone, $1365 \mathrm{~cm}^{-1}$ absorption band could be assigned for the presence of nitro compounds $\mathrm{NO}_{2}$ stretch. The bands at 1229 and $1217 \mathrm{~cm}^{-1}$ may suggest the presence of aromatic ring. The weak band at $1092 \mathrm{~cm}^{-1}$ could be assigned for $\mathrm{C}-\mathrm{O}$ stretch, most likely for secondary alcohol [14]. For the spectrum of dry henna in Fig. 6, the band at $3281 \mathrm{~cm}^{-1}$ indicates the presence of $\mathrm{OH}$ stretch or $\mathrm{H}-$ bonded $\mathrm{OH}$ stretch. The bands at 2919 and $2851 \mathrm{~cm}^{-1}$ could be assigned for methylene $\mathrm{C}-\mathrm{H}$ asym./sym. stretch. The band at $1630 \mathrm{~cm}^{-1}$ is for alkenyl $\mathrm{C}=\mathrm{C}$ stretch and may be aryl- substituted $\mathrm{C}=\mathrm{C}$. The band at 1365 $\mathrm{cm}^{-1}$-(which is weak band compared to that one at same wavenumber on Fig. 5)- could be assigned for the presence of trimethyl or "tert-butyl" (multiplet). A big band at $1027 \mathrm{~cm}^{-1}$ could be assigned for $-\mathrm{OH}$ group and/or $-\mathrm{NH}_{2}$ group or both in the same structure. 


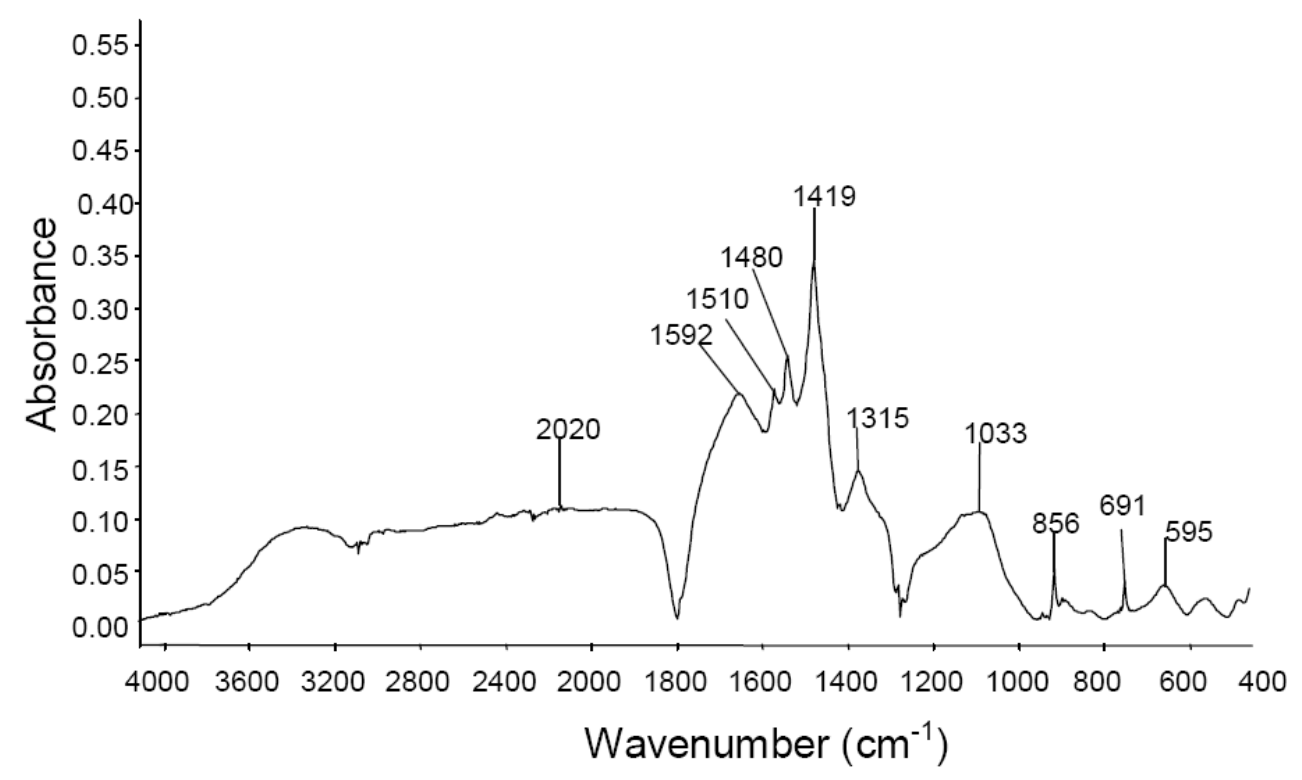

Fig. 4: Spectrum of black hair dye sample (powder).

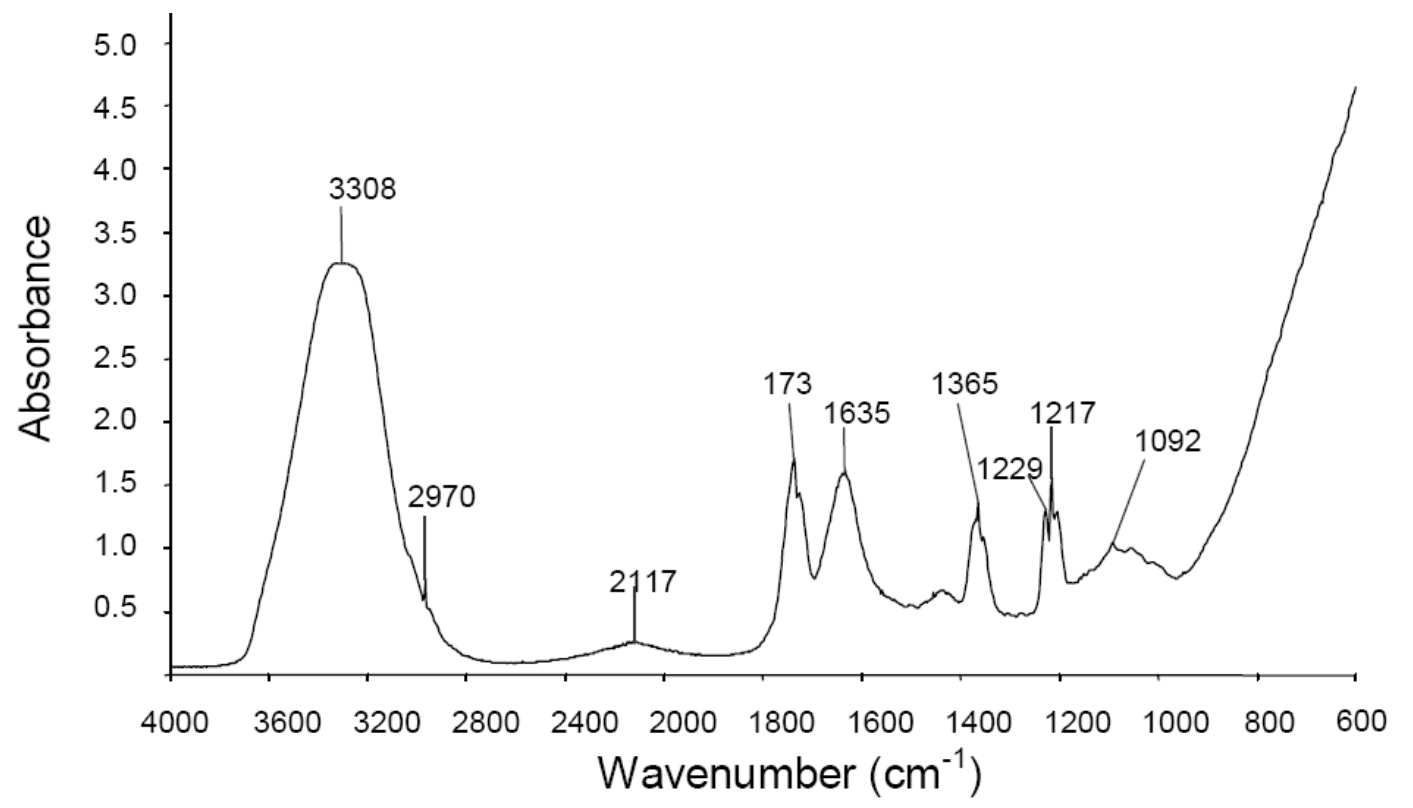

Fig. 5: Spectrum of green dye (liquid sample). 


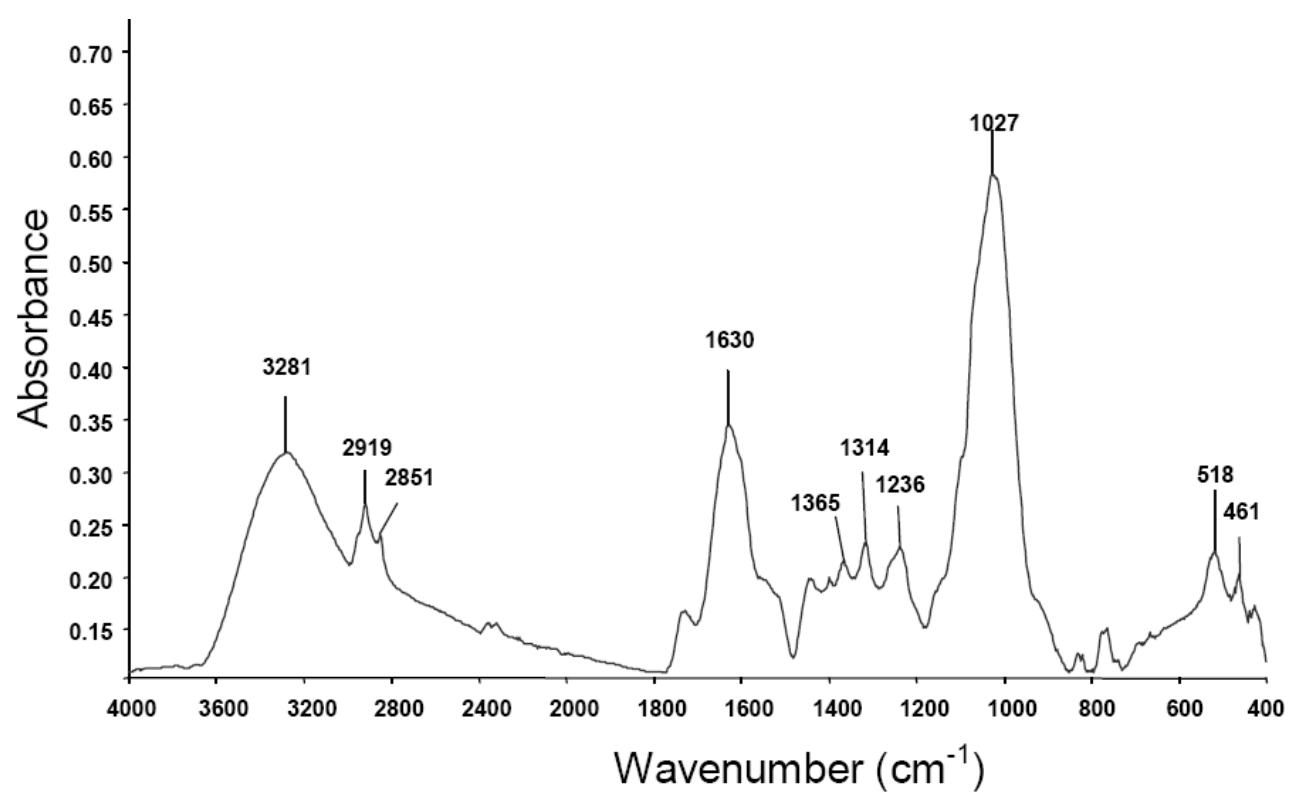

Fig. 6: Spectrum of dry henna (powder).

\subsection{Selecting the Optimal Frequency Region for Prediction}

The software Spectrum Quant Plus was used to obtain the optimal frequency region for prediction, which is calculated by multiplying the difference between each standard spectrum and the mean spectrum at each wavelength by the difference between the corresponding property concentration and the mean property concentration, and summing over all the standards. Peaks that do not correlate with the change in concentration are summed to zero, producing a spectrum that highlights the peaks that change with change in concentration, i.e. the peaks that relate to dye content. Thus, the correlation spectrum was used to choose the $3500-2650 \mathrm{~cm}^{-1}$ and $1400-800 \mathrm{~cm}^{-1}$ regions use for calculating dye contents of the samples as described by Fuller et al. [15]. High variances were seen in the same regions $\left(3000-2700 \mathrm{~cm}^{-1}\right.$ and $\left.1600-1000 \mathrm{~cm}^{-1}\right)$ for $\mathrm{C}-\mathrm{H},-\mathrm{OH},-\mathrm{NH}_{2},-\mathrm{N}=\mathrm{N}-$ and $\mathrm{C}=\mathrm{O}$ [16]. Hence, the correlation and variance spectra were used to select the best region for prediction using the PLS statistical technique to develop calibration from the FTIR spectra and chemical data. $\mathrm{R}^{2}$ and SEC from the PLS calibration were used to choose the best region for determining dye content in dyestuff samples, $3500-2650$ and $1675-1500 \mathrm{~cm}^{-1}$ region was found to be the best for determination of these types of dyestuffs.

\subsection{Statistical Analysis}

Figure 7 plots the data of actual values against the PLS FTIR-predicted values for dye content in the fabric dye samples. The best correlation obtained at the highest $\mathrm{R}^{2}(0.9321)$ and lowest SEC (1.84). Figure 8 plots the cross-validation for the determination of dye content in fabric dye samples $\left(\mathrm{R}^{2}=0.9618\right.$ and SECV $\left.=1.45\right)$. Figure 9 plots the actually prepared dye samples against the PLS FTIR spectroscopy predicted dye contents in hair 
dye samples $\left(\mathrm{R}^{2}=0.9819\right.$ and $\left.\mathrm{SEC}=1.36\right)$ and Fig. 10 the cross-validation plot for dye content in hair dye samples $\left(\mathrm{R}^{2}=0.9711\right.$ and $\left.\mathrm{SECV}=1.64\right)$.

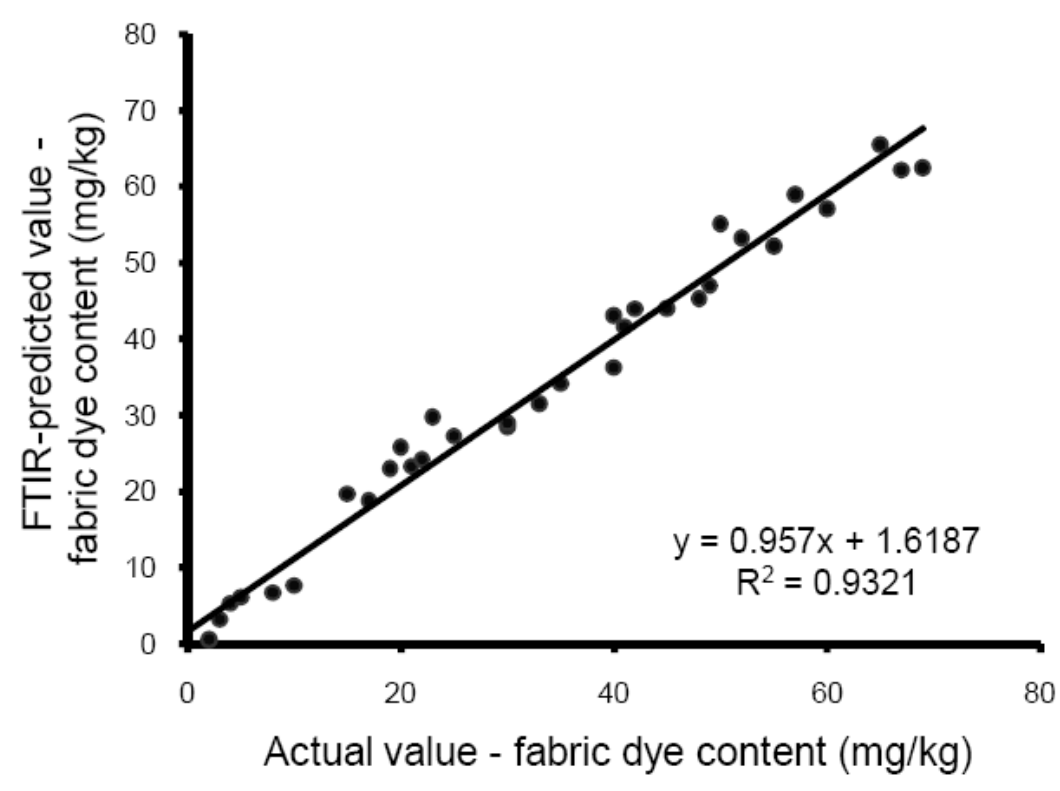

Fig. 7: Calibration of the actual precisely prepared values of fabric dye from 35 samples versus the PLS FTIR predicted values.

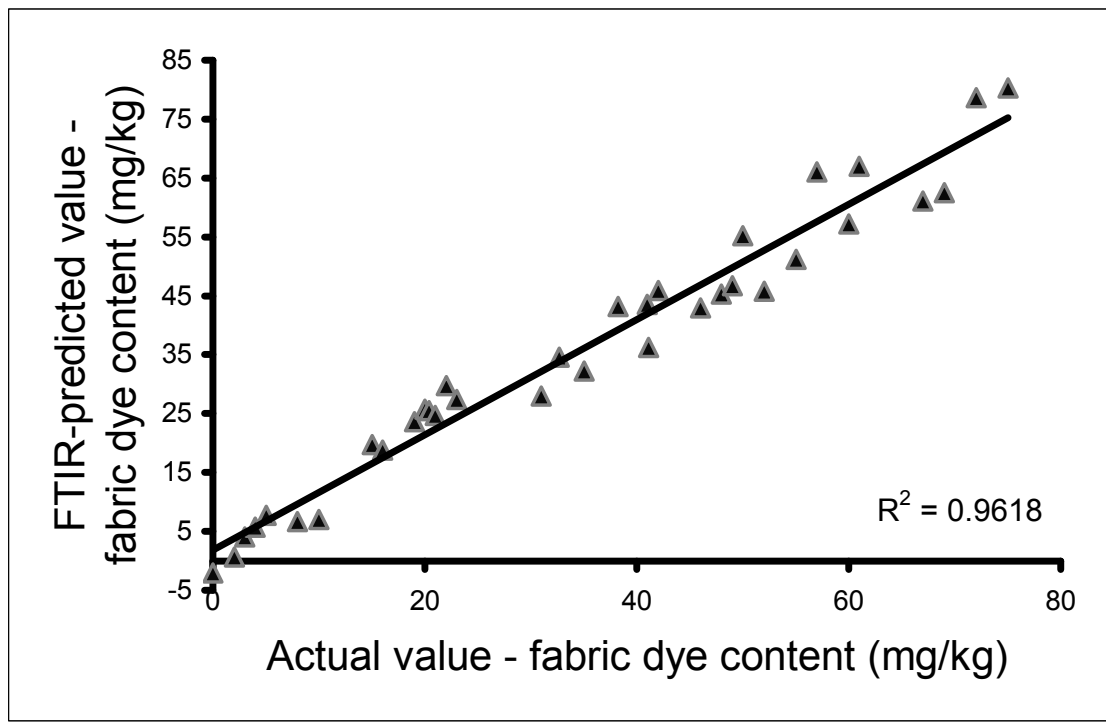

Fig. 8: Validation plot of PLS FTIR predicted values versus actual values of fabric dye content in 35 samples. 


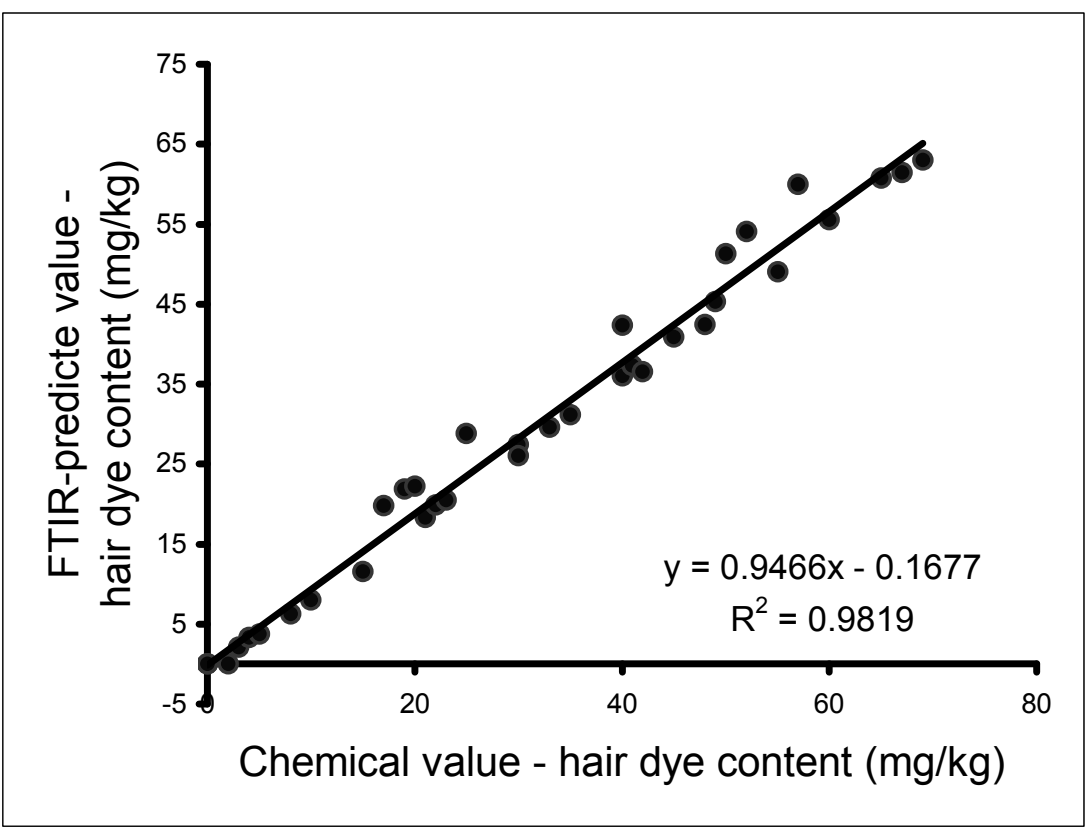

Fig. 9: Calibration plot of PLS FTIR predicted values versus chemically determined hair dye content in 35 samples.

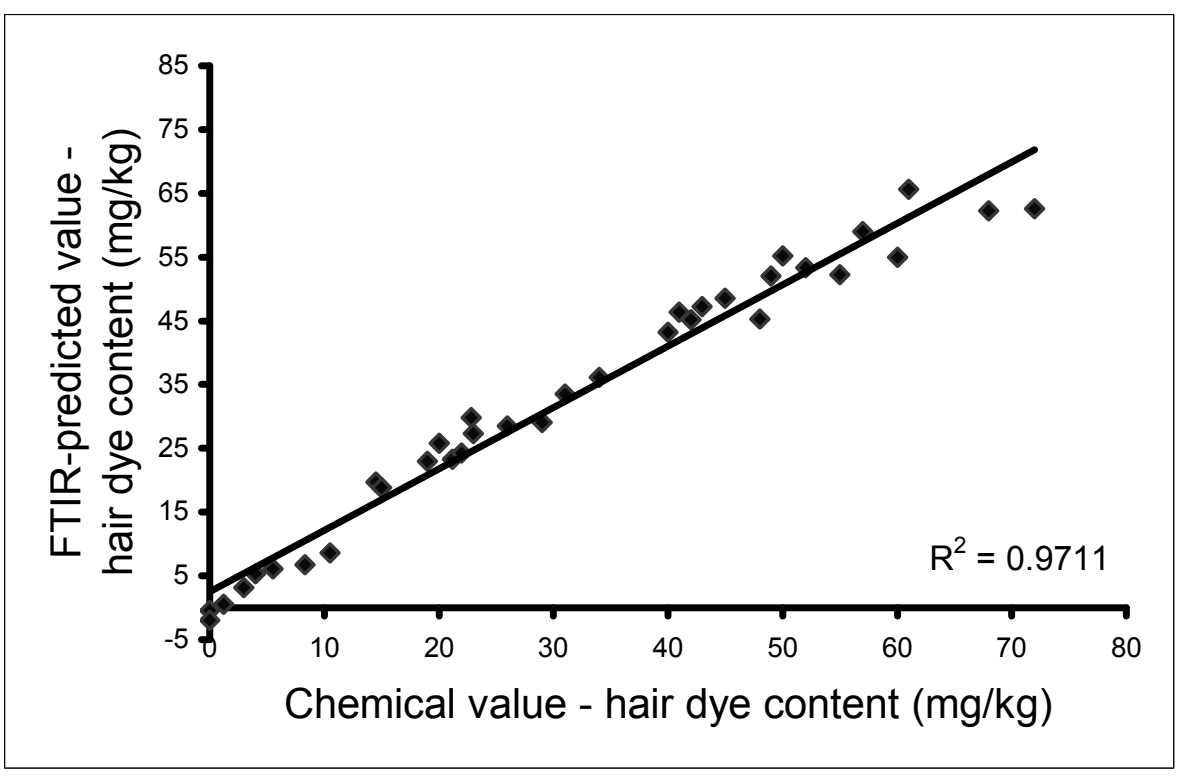

Fig. 10: Validation plot of PLS FTIR predicted values versus chemically determined hair dye content in the 35 samples.

The optimum number of factors employed in the calibrated models was indicated by the predicted residual error sum of squares (PRESS) values and were 6 and 8 for the fabric and hair dyes samples, respectively. PRESS plot is shown in Fig. 11, which also shows the $F$-test significance result for the method $(<0.05)$ and number of factors included in the calibration of fabric dye samples was 6 . The $F$ statistic for each PRESS value was calculated with all the factors prior to the number with the smallest PRESS value. The 
optimum number of factors was empirically chosen as that which gave the smallest PRESS value such that the $F$ ratio probability drops below 0.75 .

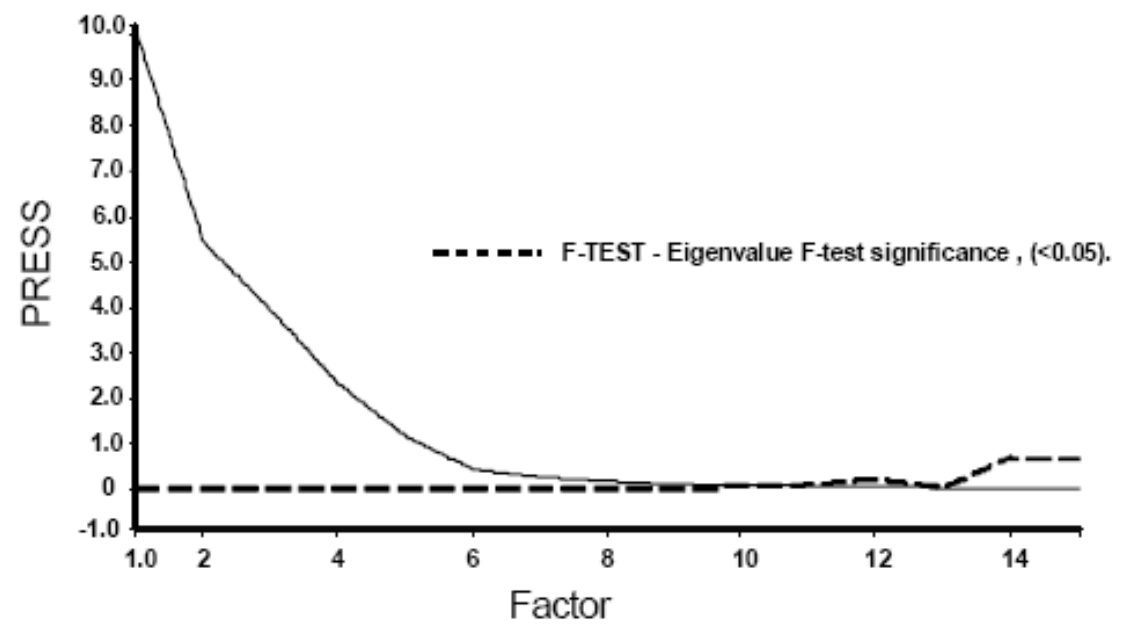

Fig. 11: Press plot obtained from cross-validation of PLS calibration for determination of fabric dye sample.

\section{CONCLUSION}

FTIR spectroscopy gives very accurate frequencies in the spectrum - this enables processing techniques such as spectral subtraction as well as it has a much shorter sampling time compared to wet chemical methods and even shorter than conventional spectroscopic techniques. FTIR spectroscopy is a useful environmental friendly method for rapid and routine detection of azo dyes as toxic dyes in such products for quality control because no chemicals are used in the detection. The full possibilities of FTIR spectroscopy are still far from being exploited.

\section{REFERENCES}

[1] P. J. W. Stone, A. L. Rhoden, L. S. Miller, D. J. Walton, A. M. McRoberts and J. Heptinstall, Polysiloxanes for Langmuir-Blodgett Applications, Thin Solid Films, Vol. 244, no. (1-2) 1012-1017, 1994.

[2] Hélène Rudyk, Michael H. Knaggs, Snezana Vasiljevic, James Hope, Chris Birkett and Ian H. Gilbert. Synthesis and Evaluation of Analogues of Congo red as Potential Compounds against Transmissible Spongiform Encephalopathies, European Journal of Medicinal Chemistry, Vol. 38, no. 6, 567-579, 2003.

[3] Katri Vikman, Studies on Fastness Properties of Ink Jet Prints Using Vibrational Spectroscopic Methods, Thesis for the degree of Licentiate of Science in Technology submitted for inspection, Espoo, November $18^{\text {th }}, 2002$. 
[4] L. Antonin, and M. Valdimir, ${ }^{13} \mathrm{C}$ and ${ }^{15} \mathrm{~N}-\mathrm{NMR}$ Studies of the Azo-hydrazone Tautomerism of Some Azo Dyes. Dyes and Pigments, Vol. 7, no.3, 171-185, 1986.

[5] S. W. Oh, M. N. Kang, C. W. Cho and M. W. Lee. Detection of Carcinogenic Amines from Dyestuffs or Dyed Substrates, Dyes and Pigments, Vol. 33, no. 2, 119 - 135, 1997.

[6] T. Bechtold, A. Turcanu, S. Geissler, and E. Ganglberger. Process Balance and Product in the Production of Natural Indigo from Polygonum tinctorium Ait, Appling Low-technology Methods, Bioresource Technology, Vol. 81, 171-177, 2002.

[7] H. Schmidt, Indigo - 100 Jahre industrielle Synthese, Chem. Unserer Zeit, Vol. 31, 121-128, 1997.

[8] G. Stoker Kerry, and T. Cooke David. Dyes from plants: Past usage, present understanding and potential, Plant growth regulation, Vol. 34, 57-69, 2001.

[9] T. Bechtold, E. Burtscher, and O. Bobleter. Konzentrationsbestimmung von Indigo in Ansatzund Prozessnadern, Text.-Prax. Int., Vol. 47, 44 - 49, 1992.

[10] J. T. Merritt III, K. R. Bock, C. B. Smith, P. J. Hauser, and W. J. Jasper, Determination of Indigo in Dye baths by Flow Injection Analysis and Redox Titrations, AATCC Rev. 1/4: 41 45, 2001.

[11] J. Dubois, F. R. van de Voort, J. Sedman, A. A. Ismail and H. R. Rawaswamy, Quantitative Fourier Transform Infrared Analysis for Anisidine Value and Aldehyde in Thermally Stressed Oils, J. Am. Oil Chem. Soc., Vol. 73, 787 - 794, 1996.

[12] K. Nakanishi, and P. H. Solomon. Infrared Absorption Spectroscopy, $2^{\text {nd }}$ Edn. Holden-Day, Boca Raton, Fl, pp. 100 - 235, 1977.

[13] N. P. G. Roeges, A Guide to the Complete Interpretation of Infrared Spectra of Organic Structures, John Wiley \& Sons Ltd, Baffins Lane, Chichester, England, p. 339, 1994.

[14] J. Coates, Interpretation of Infrared spectra, A Practical Approach, in Encyclopedia of analytical Chemistry, R. A. Meyers (ed.). John Wiley \& Sons Ltd, Chichester. pp. 10815 10837, 2000.

[15] M. P. Fuller, G. L. Ritter, and C. S. Draper, Partial Least-Square Quantitative Analysis of Infrared spectroscopic Data, Part I: Algorithm Implementation, Applied Spectroscopy, Vol. 42, no 2, 217-227, 1988.

[16] M. P. Fuller, G. L. Ritter, and C. S. Draper, Partial Least-Square Quantitative Analysis of Infrared spectroscopic Data, Part II Application to Detergent Analysis, Applied Spectroscopy, Vol. 42, no. 2, 228-235, 1988. 